\title{
Effects of Temperature and Oxygen Concentration on the Characteristics of Decarburization of 55SiCr Spring Steel
}

\author{
Yangbo LIU, ${ }^{*}$ Wei ZHANG, Qian TONG and Lifeng WANG \\ Shougang Research Institute of Technology, No 69, Yangzhuang Street, Shijingshan District, Beijing, 100043 China. \\ (Received on August 14, 2013; accepted on May 18, 2014)
}

\begin{abstract}
Effects of temperature and oxygen concentration on decarburization of $55 \mathrm{SiCr}$ spring steel were investigated at the temperature range of $500^{\circ} \mathrm{C}-1200^{\circ} \mathrm{C}$ by using a Muffle furnace (an atmosphere of ambient air) and a Simultaneous Thermal Analyzer (low oxygen concentration with $2 \% \mathrm{O}_{2}$ and $98 \% \mathrm{~N}_{2}$ ). In ambient air, the decarburization behavior can be divided roughly into five temperature ranges: $\mathrm{T} \geq 1200^{\circ} \mathrm{C}$, no decarburization; $\mathrm{TG}\left(\mathrm{A}_{3}\right.$ for $55 \mathrm{SiCr}$ when its carbon concentration equals to zero $)<\mathrm{T}<1200^{\circ} \mathrm{C}$, partial decarburization; $A_{3}<T<T G$, complete and partial decarburization; $T<A_{3}$, complete decarburization; $T<A_{1}$, no decarburization. However, it is observed that complete decarburization did not occur in all the testing temperature ranges under low oxygen concentration. For 55SiCr spring steel, decarburization behavior under low oxygen concentration can be divided into two regions: $\mathrm{T}<700^{\circ} \mathrm{C}$, no decarburization; $\mathrm{T}>700^{\circ} \mathrm{C}$, only partial decarburization. Lower oxygen concentration results in decrease in a growth rate of the oxide scale and leads to different characteristics of decarburization.
\end{abstract}

KEY WORDS: 55SiCr spring steel; complete decarburization; partial decarburization; oxygen concentration; growth rate of oxide scale.

\section{Introduction}

$55 \mathrm{SiCr}$ is a kind of high-grade steel applied in automotive suspension spring of which good performance under fatigue loading is requested. Surface decarburization dramatically compromises fatigue properties of spring steels. ${ }^{1,2)}$ Decarburization is a phenomenon that both microstructure and carbon concentration in surface layer were changed when steels were heated under oxygen atmosphere. Decarburization was influenced by many factors, such as heating temperature, holding time, atmosphere in furnaces and chemical compositions. ${ }^{3,4)}$

It was reported that decarburization characteristics depend on heating temperature. ${ }^{5-7)}$ For hypoeutectoid steels, decarburization characteristics are divided into three regions. In the region (a) $\mathrm{TG}\left(\mathrm{A}_{3}\right.$ for pure iron) $<\mathrm{T}<1200^{\circ} \mathrm{C}$, carbon concentration changes freely, and only partial decarburization is observed. In the region (b) $675^{\circ} \mathrm{C}<\mathrm{T}<\mathrm{TG}$, ferrite layer is formed in surface. In the region (c) $\mathrm{T}<675^{\circ} \mathrm{C}$ or $700^{\circ} \mathrm{C}$, no decarburization is found. Nomura et al. ${ }^{8)}$ reported a model predicting the ferrite decarburizing depth of spring steel assuming that no oxidation occurred. Choi et al. ${ }^{9)}$ proposed a model to explain the coupled growth of oxide layers and ferrite decarburization in steels based on phase transformation and diffusion calculation during heating and cooling. Badu et al. ${ }^{10)}$ investigated the influence of relative humidity on oxidation and decarburization.

All the mentioned experiments and models were conduct-

* Corresponding author: E-mail: liuyangbo913@126.com

DOI: http://dx.doi.org/10.2355/isijinternational.54.1920 ed or obtained in ambient air. In fact, in order to prevent decarburization and oxidation, adjusting air to combustion gas ratio to form reducing atmosphere in reheating furnaces has already been used practically. However, effect of oxygen concentration on the characteristics of decarburization has not been fully investigated. For instance, which method is more feasible to reduce the thickness of decarburization, increasing temperature or decreasing oxygen concentration? Is it possible to eliminate complete decarburization by decreasing oxygen concentration? It is significantly valuable to understand the effect of oxygen concentration on the characteristics of decarburization for processes such as reheating billets and heat treating steel parts. For these purposes, the effects of temperature and oxygen concentration on the characteristics of decarburization of $55 \mathrm{SiCr}$ spring steel were investigated in this study.

\section{Experimental Procedure}

The chemical compositions of the steel used in this study corresponds to $55 \mathrm{SiCr}$ steel. The average chemical compositions are C: $0.53 \%$, Si: $1.51 \%, \mathrm{Mn}: 0.69 \%, \mathrm{Cr}: 0.70 \%, \mathrm{P}$ : $0.01 \%, \mathrm{~S}: 0.009 \%, \mathrm{Al}: 0.031 \%$ and $\mathrm{Fe}$ in balance. Steel ingots were cast by vacuum induction melting furnace and then forged into $\Phi 30 \mathrm{~mm}$ bars.

Two experiments were conducted to investigate effect of oxygen concentration on the characteristics of decarburization. Experiment I: specimens were prepared as $10 \mathrm{~mm} \times 10$ $\mathrm{mm} \times 10 \mathrm{~mm}$ cubes. These specimens were heated at $650^{\circ} \mathrm{C}-$ $1200^{\circ} \mathrm{C}$ for $60 \mathrm{~min}$ in ambient air in a Muffle furnace. Specimens were placed in a Muffle furnace when temperature 
became stable at the set temperature and cooled in the air immediately after heating. The cooling rate was approximately $1^{\circ} \mathrm{C} / \mathrm{s}$ in the temperature range from $800^{\circ} \mathrm{C}$ to $650^{\circ} \mathrm{C}$. Experiment II: specimens were machined from bars with their longitudinal axis parallel to rolling direction; each specimen had a diameter of $4.5 \mathrm{~mm}$ and a length of $6 \mathrm{~mm}$. Those specimens were heated at $500^{\circ} \mathrm{C}-1200^{\circ} \mathrm{C}$ for $30 \mathrm{~min}$ under low oxygen concentration with an atmosphere of $2 \%$ $\mathrm{O}_{2}$ and $98 \% \mathrm{~N}_{2}$ in the Simultaneous Thermal Analyzer (STA449C). Nitrogen protection was adopted in order to avoid decarburization during heating and cooling process. The cooling rate was set at $1^{\circ} \mathrm{C} / \mathrm{s}$.

Amount of oxidation was measured by the weight loss method and the mass gain method for Experiment I and Experiment II respectively. Specimens were weighed before heating, and re-weighed after removing the oxide scale formed during heating. As a result, the weight loss for Experiment I was obtained. The weight increase for Experiment II during heating was monitored automatically and continuously by the Simultaneous Thermal Analyzer. The oxide scale was assumed to be FeO.

$$
\mathrm{Fe}+\frac{1}{2} \mathrm{O}_{2}=\mathrm{FeO}
$$

Weight loss was caused by peeling of scale while weight gain was due to absorption of oxygen. The weight loss for Experiment I was the weight of Fe; while the weight gain for Experiment II was the weight of oxygen. The weights of $\mathrm{FeO}$ for both Experiments were derived from the weight gain or loss. Thickness of oxide scale was calculated from dividing the weight of $\mathrm{FeO}$ by the density of scale as shown in Eqs. (2) and (3).

$$
\begin{gathered}
x=\frac{\frac{72}{56} \Delta w_{L}}{6 a^{2} \rho_{F e O}} . \\
x=\frac{\frac{72}{16} \Delta w_{G}}{2 \pi r h \rho_{F e O}}
\end{gathered}
$$

where $x$ is the thickness of oxide scale, $\Delta w_{L}$ is the weight loss, $\Delta w_{G}$ is the weight gain, $p_{\mathrm{FeO}}$ is the density of $\mathrm{FeO}$ scale, and $a, r$ and $h$ are the geometric dimensions for specimens of Experiment I and Experiment II.

All decarburized specimens were polished and etched with 4 vol\% nital for microstructure observation. Measurement of decarburized depth was performed by micrographic method according to the national standard of China GB/T 224-2008.

\section{Results}

3.1. Experiment I: Decarburization in Muffle Furnace

Figure 1 demonstrates microstructures of specimens in
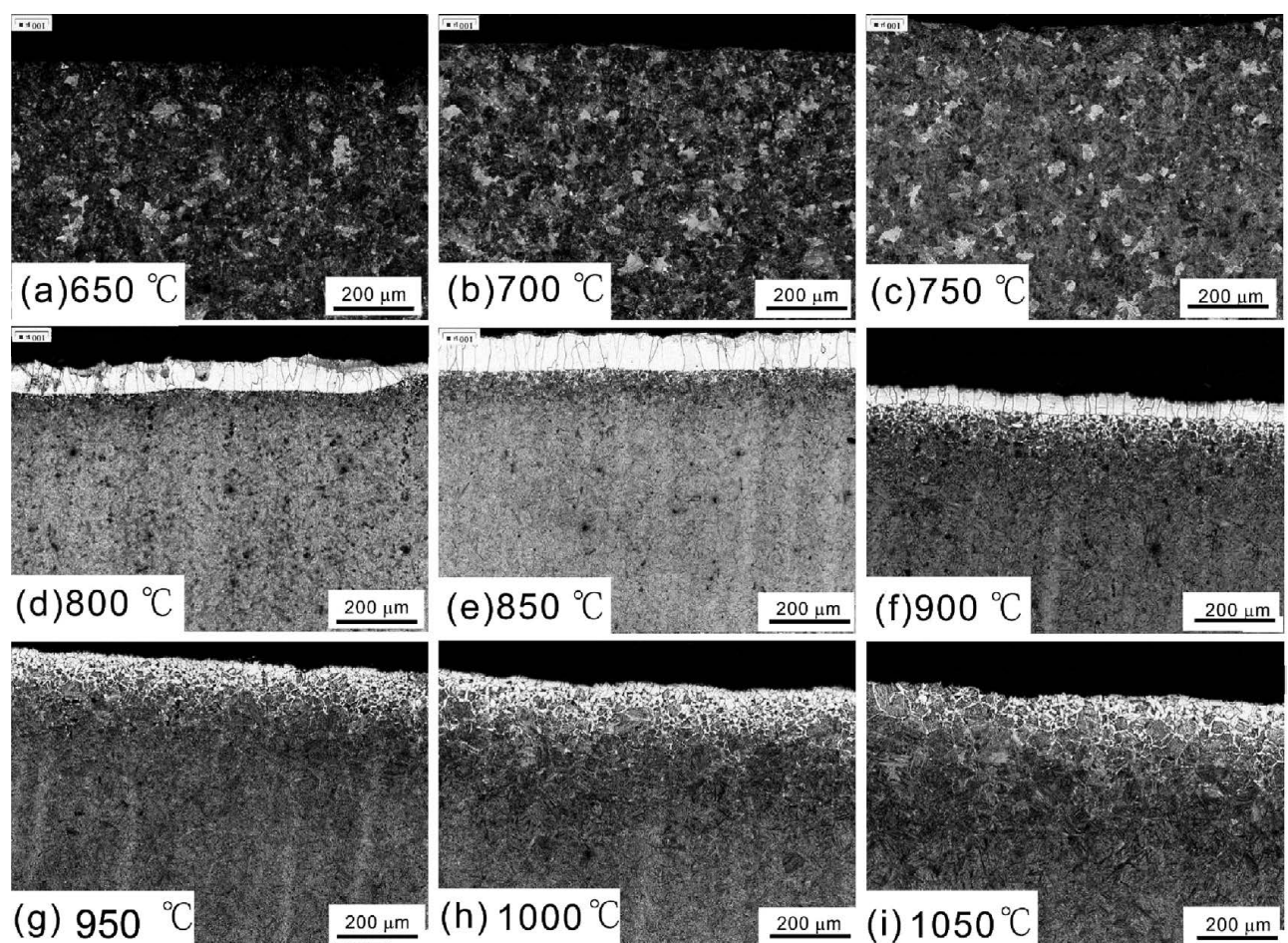

\section{(g) 950}
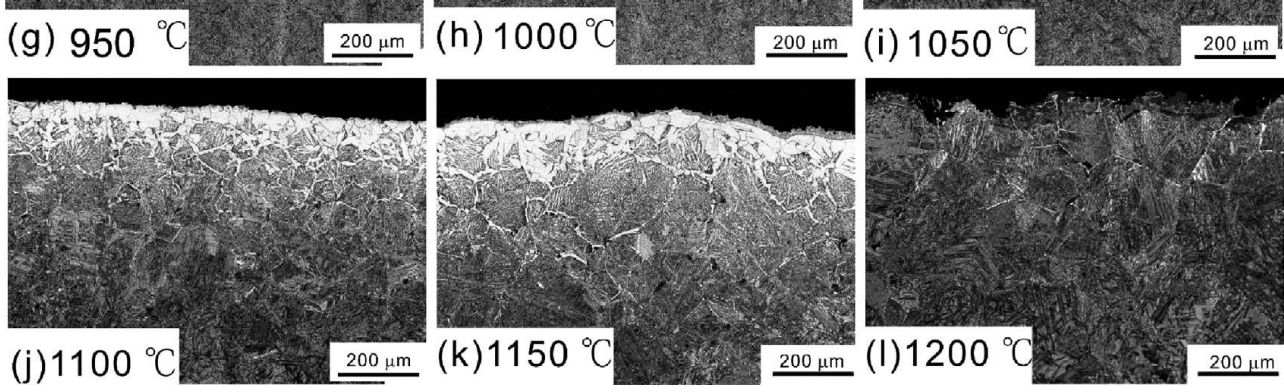

Fig. 1. Microstructures of $55 \mathrm{SiCr}$ after heated at $650^{\circ} \mathrm{C}-1200^{\circ} \mathrm{C}$ for $60 \mathrm{~min}$ in ambient air. 
experiment I. It is observed that temperature has an important role on decarburization. With the increase of temperature from $650^{\circ} \mathrm{C}$ to $1200^{\circ} \mathrm{C}$, the decarburized depth increases significantly, and the characteristics of decarburization change dramatically.

No decarburization is observed below $750^{\circ} \mathrm{C}$. Only complete decarburization is observed in the specimen heated at $800^{\circ} \mathrm{C}$ while both complete and partial decarburization are

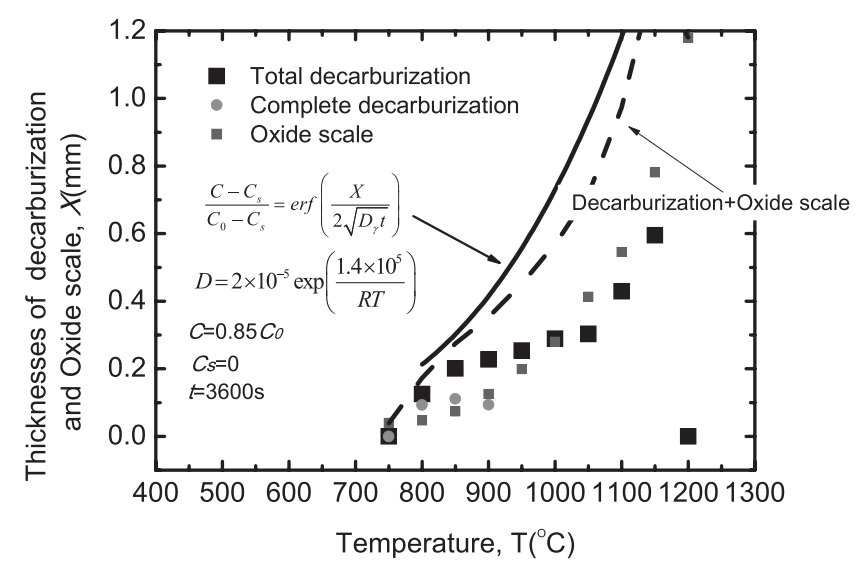

Fig. 2. The relationship among thicknesses of total decarburization, complete decarburization, oxide scale and heating temperature in ambient air for $60 \mathrm{~min}$. observed in that at $850^{\circ} \mathrm{C}$ and $900^{\circ} \mathrm{C}$. Only partial decarburization is found at the range of $950^{\circ} \mathrm{C}-1150^{\circ} \mathrm{C}$. No decarburization is detected at $1200^{\circ} \mathrm{C}$.

The relationship of total decarburization thicknesses, complete decarburization thicknesses, oxide scale thicknesses and heating temperature in ambient air for $60 \mathrm{~min}$ is shown in Fig. 2. The thickness of total decarburization increases with temperature rising, especially above $1000^{\circ} \mathrm{C}$. However, the thickness of total decarburization at $1200^{\circ} \mathrm{C}$ drops to zero. Besides, maximum thickness of complete decarburization is found at $850^{\circ} \mathrm{C}$. The thickness of oxide scale increases continually from $0.03 \mathrm{~mm}$ to $1.2 \mathrm{~mm}$ with temperature rising from $750^{\circ} \mathrm{C}$ to $1200^{\circ} \mathrm{C}$.

\subsection{Experiment II: Decarburization in Simultaneous Thermal Analyzer}

Figure 3 summarizes microstructures of specimens in experiment II. It is obvious that oxygen concentration has an important role on decarburization. First of all, complete decarburization is not found in all specimens heated in the temperature range of $500^{\circ} \mathrm{C}-1200^{\circ} \mathrm{C}$. Only partial decarburization is observed in the range of $800^{\circ} \mathrm{C}-900^{\circ} \mathrm{C}$ in which complete decarburization is expected. Secondly, decarburization is still observed at $1200^{\circ} \mathrm{C}$. Thirdly, a thin decarburized layer about $2 \mu \mathrm{m}$ is found at $700^{\circ} \mathrm{C}$ and $750^{\circ} \mathrm{C}$. All these three results are not observed in experiment I.
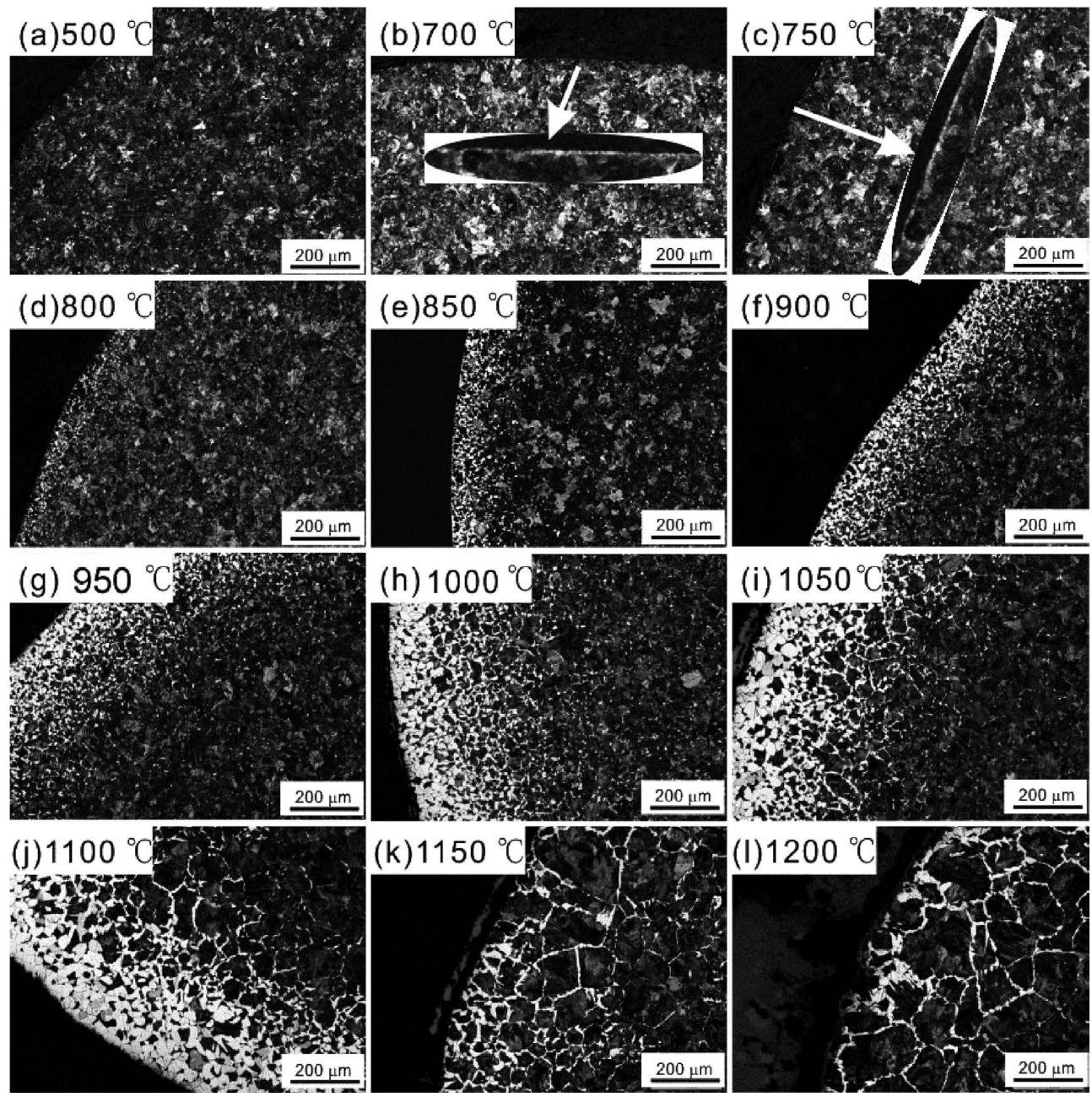

Fig. 3. Microstructures of $55 \mathrm{SiCr}$ after heated at $500^{\circ} \mathrm{C}-1200^{\circ} \mathrm{C}$ for $30 \mathrm{~min}$ in the atmosphere of $2 \% \mathrm{O}_{2}$ and $98 \% \mathrm{~N}_{2}$. 


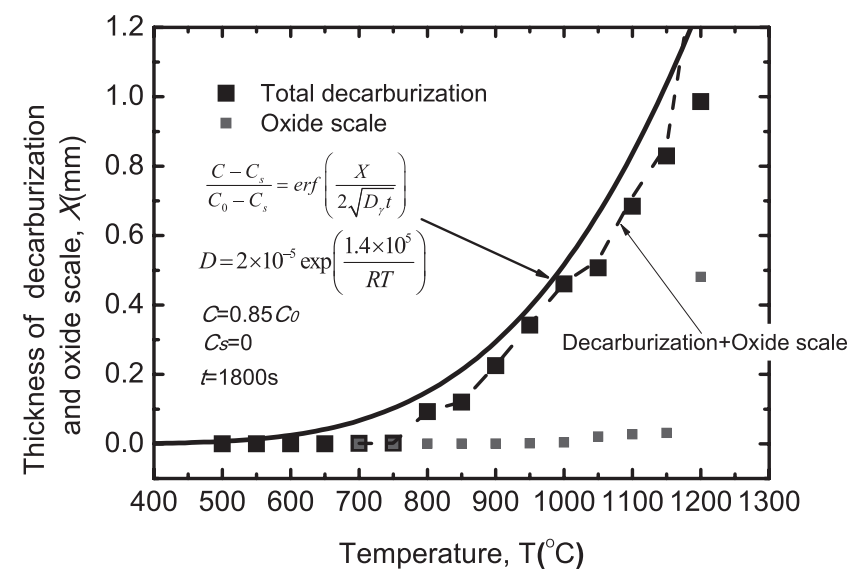

Fig. 4. The relationship among thicknesses of total decarburization, oxide scale and heating temperature for $30 \mathrm{~min}$ in the atmosphere of $2 \% \mathrm{O}_{2}$ and $98 \% \mathrm{~N}_{2}$.

The relationship among the thicknesses of total decarburization, oxide scale and heating temperature is shown in Fig. 4. Similar to the phenomenon observed in ambient air, the thickness of total decarburization increases with temperature. However, unlike that in ambient air, the thickness still increases at $1200^{\circ} \mathrm{C}$. The oxidation behavior is quite different from that in ambient air. In the temperature range below $900^{\circ} \mathrm{C}$, the thickness of oxide scale is less than $1 \mu \mathrm{m}$; in the temperature range from $900^{\circ} \mathrm{C}$ to $1150^{\circ} \mathrm{C}$, it increases slowly from $1 \mu \mathrm{m}$ to $30 \mu \mathrm{m}$; at $1200^{\circ} \mathrm{C}$, it increases suddenly to $0.5 \mathrm{~mm}$.

\section{Discussion}

\subsection{Formation Mechanism of Decarburization in Ambient Air}

When steel is heated at a high temperature, the surface layer will react with the oxygen in the atmosphere to cause oxidization and decarburization. When the rate of oxidization is faster than that of decarburization, decarburized metal is rapidly consumed by oxidation, and then only oxide scale can be observed on the surface of steel without any decarburization zone under the scale. That is the reason that no decarburization was observed at $1200^{\circ} \mathrm{C}$ in ambient air, which is consistent with Chen et al.'s observation. ${ }^{11)}$ It is feasible to decrease the thickness of decarburization by increasing heating temperature to $1200^{\circ} \mathrm{C}$ in ambient air. On the other hand, when decarburization is faster than oxidization, decarburized layer and oxidized scale can be formed simultaneously. Therefore, the following two types of decarburization will occur.

1) Partial decarburization is the loss of carbon from the surface of the steel specimen to a level below the carbon content of the unaffected interior but greater than the roomtemperature solubility limit of carbon in ferrite. According to phase diagram of $55 \mathrm{SiCr}$ calculated by Thermo-Calc ${ }^{\mathrm{TM}}$ shown in Fig. 5, ferrite is not stable and cannot be formed in the temperature range $\mathrm{T}>\mathrm{TG}$. $\mathrm{TG}$ was defined as $\mathrm{A}_{3}$ for pure iron by previous researchers, ${ }^{5)}$ however it would be more accurate to define as $\mathrm{A}_{3}$ for $55 \mathrm{SiCr}$ when carbon concentration equals to zero. Under this condition, the concentration profiles of carbon changes as a function of time and

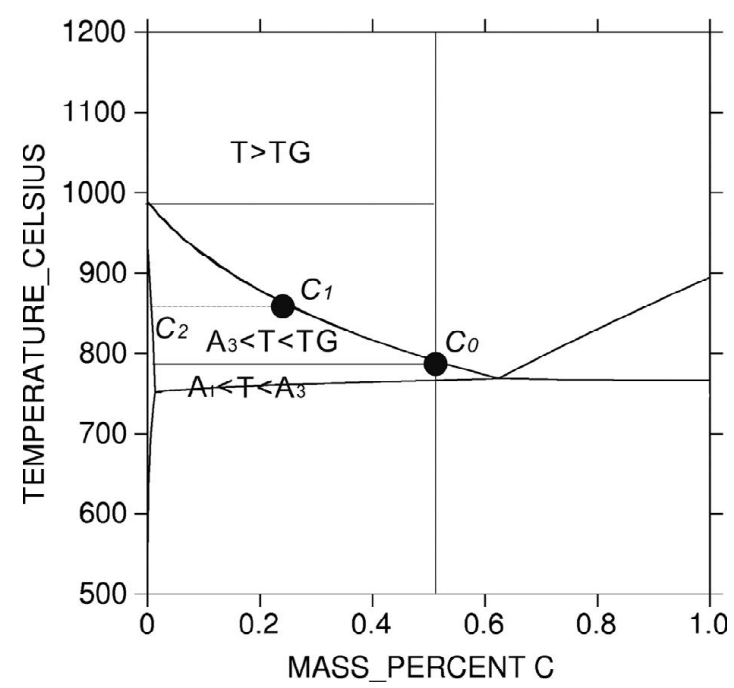

Fig. 5. Phase diagram of $55 \mathrm{SiCr}$ calculated by Thermo-Calc ${ }^{\mathrm{TM}}$.

temperature of heating. Therefore the concentration profile of carbon changes with distance from the surface as shown in Fig. 6(a). Ferrites nucleate at austenite grain boundaries, and then pearlites form during the cooling period. As a result, partial decarburization appears on the surfaces as shown in Figs. 1(g)-1(k).

2) Complete decarburization is the loss of carbon on the surface of a steel specimen to a level below the solubility limit of carbon in ferrite to produce entirely ferrite surface layers. Complete decarburizations can be divided into two categories: complete decarburization as shown in Fig. 1(d) at $800^{\circ} \mathrm{C}$ and complete decarburization plus partial decarburization as shown in Figs. $1(\mathrm{e})-1(\mathrm{f})$ at $850^{\circ} \mathrm{C}$ and $900^{\circ} \mathrm{C}$. According to the phase diagram shown in Fig. 5, the austenite is not stable and has to separate out some ferrites to regain the equilibrium when the carbon concentration decreases to $C_{l}$ (the equilibrium concentration of austenite at the interface of ferrite and austenite at the given temperature) in the temperature range $\mathrm{A}_{3}<\mathrm{T}<\mathrm{TG}$. In the meanwhile, carbon is transported to transformation front from interior austenite, and carbon in the front is transported to the surface. The concentration profile of carbon changing with distance from the surface is shown in Fig. 6(b). The ferrite grains grow perpendicular to the specimen surface and complete decarburization forms during this process. Partial decarburization presents at interior in which the austenite with lower carbon content than $C_{0}$ during cooling period. As a result, both complete decarburization and partial decarburization appear on the surface as shown in Fig. 1(f).

Another type of complete decarburization is that only complete decarburization is observed. It occurs in $\mathrm{A}_{1}<\mathrm{T}<\mathrm{A}_{3}$. Ferrite and austenite coexist at this temperature range. Carbon is depleted in austenite and transported to surface through ferrite. At the same time, the austenite transforms to ferrite. Accordingly, the concentration profile of carbon changes with distance from surface as shown in Fig. 6(c). For convenient of expression, the carbon concentration of the inner is assumed to be $C_{0}$ though steel containing two phase structures and the carbon concentration fluctuating at those temperatures. Therefore, there is only ferrite perpendicular to the surface, and the microstructure is not affected 


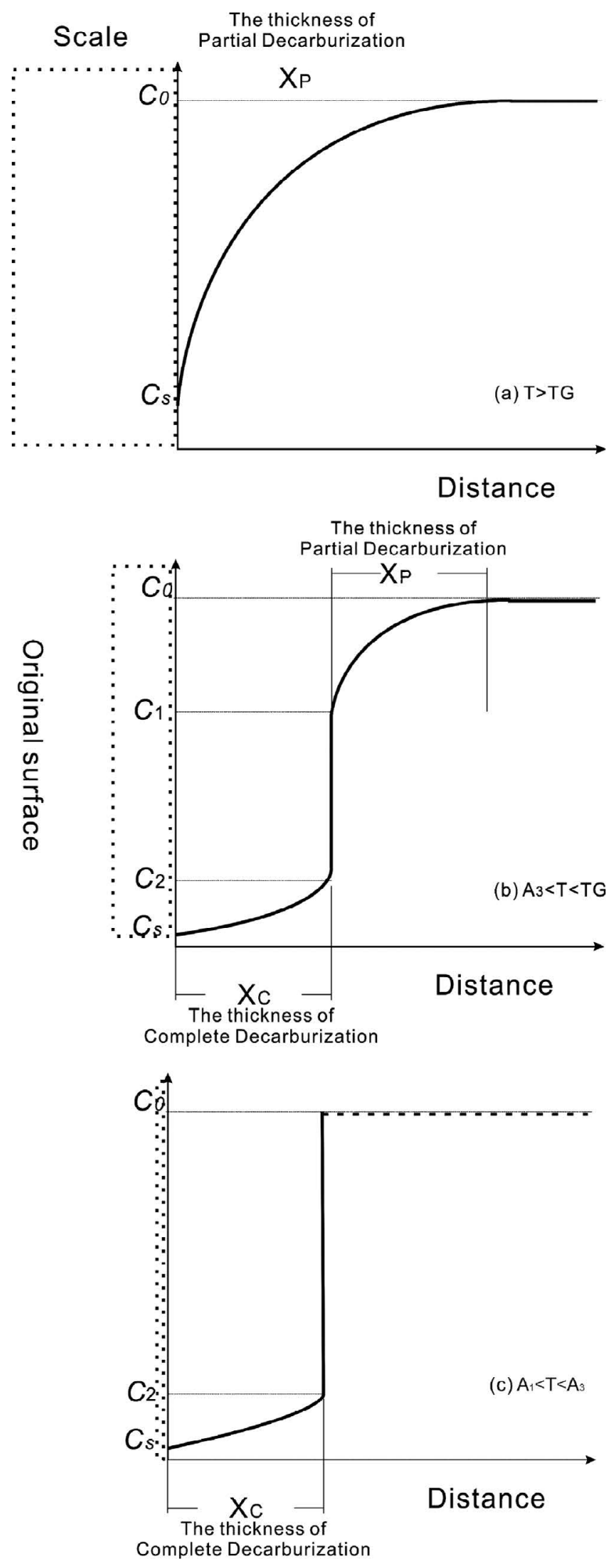

Fig. 6. Schematic carbon concentration profiles under different conditions. (a) $\mathrm{T}>\mathrm{TG}$, (b) $\mathrm{A}_{3}<\mathrm{T}<\mathrm{TG}$ and (c) $\mathrm{A}_{1}<\mathrm{T}<\mathrm{A}_{3}$.

even in the vicinity of ferrite as shown in Fig. 1(d). As a result, only complete decarburization appears on the surface.

The microstructure of $55 \mathrm{SiCr}$ consists of $\alpha$-Fe and $\mathrm{Fe}_{3} \mathrm{C}$ in $\mathrm{T}<\mathrm{A}_{1}$. Complete decarburization could form by cementite dissolution in this temperature range. Decarburization usually takes place at temperatures above about $700^{\circ} \mathrm{C}$ as reported by other researchers. ${ }^{12)}$ Baud et al ${ }^{10)}$ reported that decarburization was measurable only after a period of $32 \mathrm{~h}$

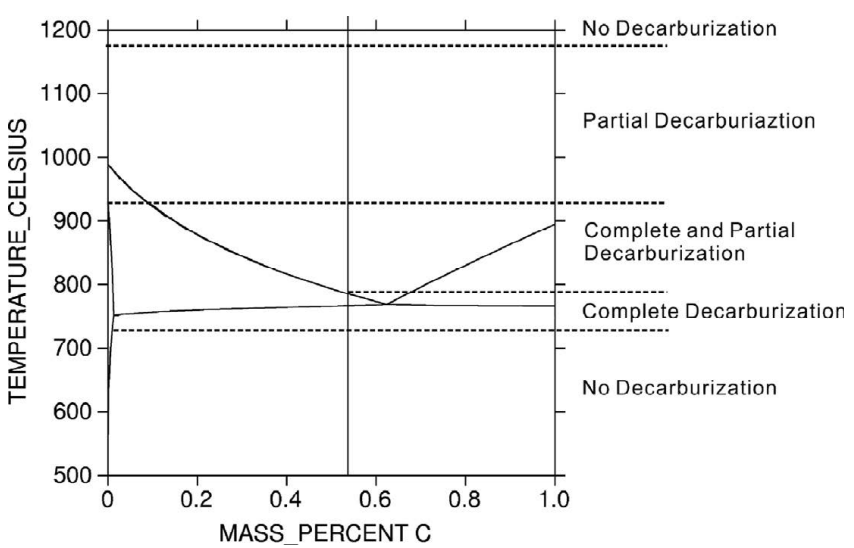

Fig. 7. Classification of decarburization types according to temperature in the phase diagram of $55 \mathrm{SiCr}$ heated in ambient air.

heated at $700^{\circ} \mathrm{C}$ in ambient air. As expected, no decarburization was found in the specimens heated at temperature lower than $A_{1}$. This could be explained as follows: a) the diffusion coefficient of carbon is low because of low temperature, so decarburization is limited; b) oxidation is faster than decarburization and consumes the decarburized layer.

According to the analysis above, the decarburization behavior of $55 \mathrm{SiCr}$ is divided roughly into five regions as shown in Fig. 7. In the region (a) $\mathrm{T} \geq 1200^{\circ} \mathrm{C}$, no decarburization occurs. In the region (b) $\mathrm{TG}<\mathrm{T}<1200^{\circ} \mathrm{C}$, only partial decarburization is found. In the region (c) $\mathrm{A}_{3}<\mathrm{T}<\mathrm{TG}$, both complete and partial decarburization are observed. In the region (d) $\mathrm{T}<\mathrm{A}_{3}$, only complete decarburization is found. In the region (e) $\mathrm{T}<\mathrm{A}_{1}$, no decarburization occurs.

\subsection{Effect of Oxygen Concentration on the Character- istics of Decarburization}

Two important experimental facts are observed in Experiment II: complete decarburization disappears, and temperature range of decarburization extends when $55 \mathrm{SiCr}$ is heated under low oxygen concentration compared with that in ambient air.

Complete decarburization of steels involves the following basic steps: (a) removal of carbon in solution by reaction at surface with oxygen, (b) diffusion of carbon through early formed ferrite from transformation front to the surface and (c) transformation from austenite to ferrite.

It is said that the carbon content at the metal/scale interface is constant, as long as $\mathrm{FeO}$ remains in contact with the steel, thus the driving force for carbon diffusion is also constant in the presence of a scale. ${ }^{13)}$ However, the thickness of oxide scale is less than $1 \mu \mathrm{m}$ under low oxygen concentration when temperature is below $900^{\circ} \mathrm{C}$ as shown in Fig. 4. Besides, $55 \mathrm{SiCr}$ contains relatively higher $\mathrm{Si}$ content of $1.5 \%$. The steel with such high Si content could form internal $\mathrm{SiO}_{2}$ precipitates or external $\mathrm{SiO}_{2}$ scale. More detailed investigations about the scale structure are needed in further research. Generally, low oxygen concentration favors the external scale formation, and carbon activity at the subsurface region of the steel is high, since equilibrium partial pressure of oxygen at the scale/steel interface must be different with $\mathrm{SiO}_{2}$ scale formation. Therefore, decreasing 
oxygen concentration leads to an increase of the surface carbon concentration balanced with atmosphere, $C_{s}$. As shown in Fig. 8, if $C_{s}>C_{2}$ (the equilibrium concentration of ferrite at the interface of ferrite and austenite), the transportation of carbon from the transformation front to the surface is impossible, the decarburized austenite stays stable, and the transformation from austenite to ferrite could cease. Then, complete decarburization would not form. According to the calculated phase diagram of $55 \mathrm{SiCr}$, the value of $C_{2}$ is in the range of $0-0.01 \%$ for the temperature range of $800-900^{\circ} \mathrm{C}$ in which complete decarburization is observed in ambient air. It is difficult to monitor $C_{s}$ during decarburization. Wen et al. ${ }^{14)}$ reported that $C_{s}$ equals to $0.0132 \%$, equilibrium with the atmosphere in the reheating furnace which normally contains $5 \%-10 \%$ oxygen. $C_{s}$ in Experiment II has to be higher than $0.0132 \%$ because of lower oxygen concentration. Thus, the complete decarburization is suppressed under low oxygen concentration because $C_{S}$ is higher than $C_{2}$.

The oxidization and decarburization can occur simultaneously when steels are heated at high temperatures. The thickness of decarburization observed could be the difference between decarburization and oxidization.

Decarburization without considering oxidization is controlled by the diffusion of carbon in iron matrix. ${ }^{15)}$ The basic governing equation of the diffusion of interstitial carbon in the iron matrix is known as Fick's second law.

$$
\frac{C-C_{s}}{C_{0}-C_{s}}=\operatorname{erf}\left(\frac{X}{2 \sqrt{D_{\gamma} t}}\right)
$$

where $C$ is the carbon concentration, $C_{0}$ is the initial carbon composition before decarburization, $X$ is the thickness of decarburization, $t$ is time, and $D_{\gamma}$ is carbon diffusivity. $D_{\gamma}$ is known to be temperature dependent, as expressed in

$$
D_{\gamma}=D_{0} \exp \left(-\frac{Q}{R T}\right)
$$

where $D_{0}$ is the temperature-independent pre-exponential,

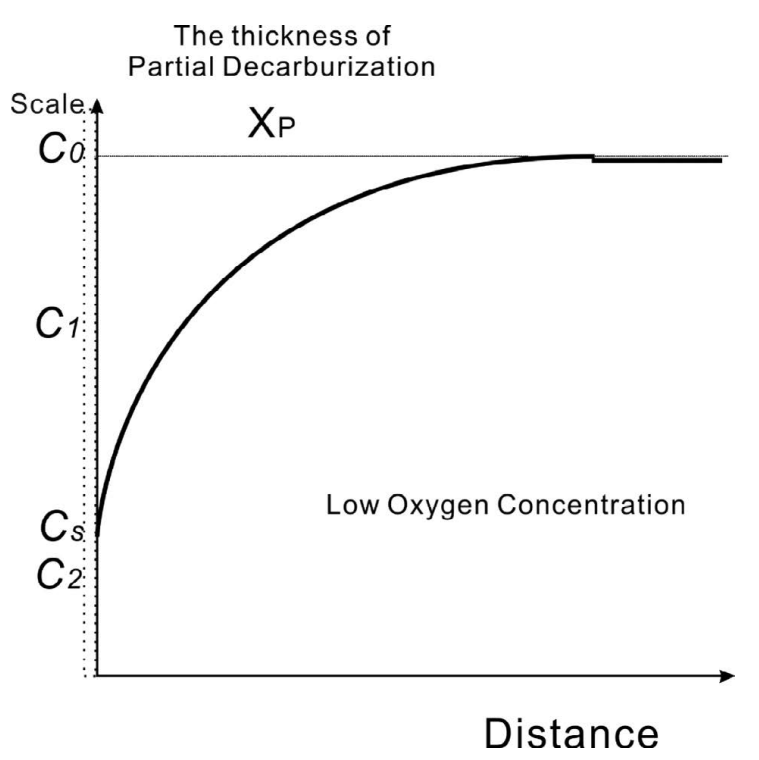

Fig. 8. Schematic carbon concentration profile under low oxygen concentration.
$2.0 \times 10^{-5} \mathrm{~m}^{2} / \mathrm{s} ; Q$ is the activation energy, $1.4 \times 10^{5} \mathrm{~J} / \mathrm{mol} ;^{6)} R$ is the gas constant; and $T$ is the absolute temperature.

The oxidation rates are found to be strongly influenced by the oxygen concentration in the atmosphere. Lower oxygen concentrations result in decrease in the growth rate of oxide scale. ${ }^{16)}$ Therefore, the thicknesses of oxide scale for specimens heated in ambient air are much higher than those for specimens heated under low oxygen concentration as shown in Figs. 2 and 4.

The decarburization thicknesses of Experiment I and II are present in Figs. 2 and 4 respectively. In Fig. 2, experimental results do not match well with the calculated values by Eq. (4) especially above $900^{\circ} \mathrm{C}$; while the thicknesses of decarburization plus oxide scale correspond closely to the calculated values by Eq. (4), which means that oxidation plays a very important role during decarburization. The thickness of oxide scale at $1200^{\circ} \mathrm{C}$ is $1.2 \mathrm{~mm}$, and it approaches to the calculated value. In other words, severe oxidation rapidly consumes the decarburized layer. Similarly, the thickness of oxide scale at $750^{\circ} \mathrm{C}$ is $0.04 \mathrm{~mm}$, and it approaches to the predicted value $(0.06 \mathrm{~mm})$ by the model proposed by Nomura et al. ${ }^{8)}$

However, in Fig. 4, the experimental results and the calculated values by Eq. (4) match precisely. As also shown in Fig. 4, the thicknesses of oxide scale are less than $0.03 \mathrm{~mm}$ below $1150^{\circ} \mathrm{C}$. From this point of view, oxidation rate is very slow because of low oxygen concentration. Those experimental results suggest that by reducing oxygen concentration, the thicknesses of oxide scale are reduced, but decarburization observed is thicker than that in ambient air. Because of insufficient oxidation, the thickness of decarburization still increases with temperature at $1200^{\circ} \mathrm{C}$ in Experiment II. That is to say, it is impossible to reduce the thickness of carburization by increasing temperature when heated in low oxygen concentration atmosphere. The slight decarburized layer is found at $700^{\circ} \mathrm{C}$ and $750^{\circ} \mathrm{C}$ because of very limited oxidation likewise.

According to the analysis above, the decarburization behavior for $55 \mathrm{SiCr}$ spring steels heated under low oxygen concentration can be divided into two regions as shown in Fig. 9. In the temperature lower than $700^{\circ} \mathrm{C}$, no decarburization occurs. In the temperature higher than $700^{\circ} \mathrm{C}$, only

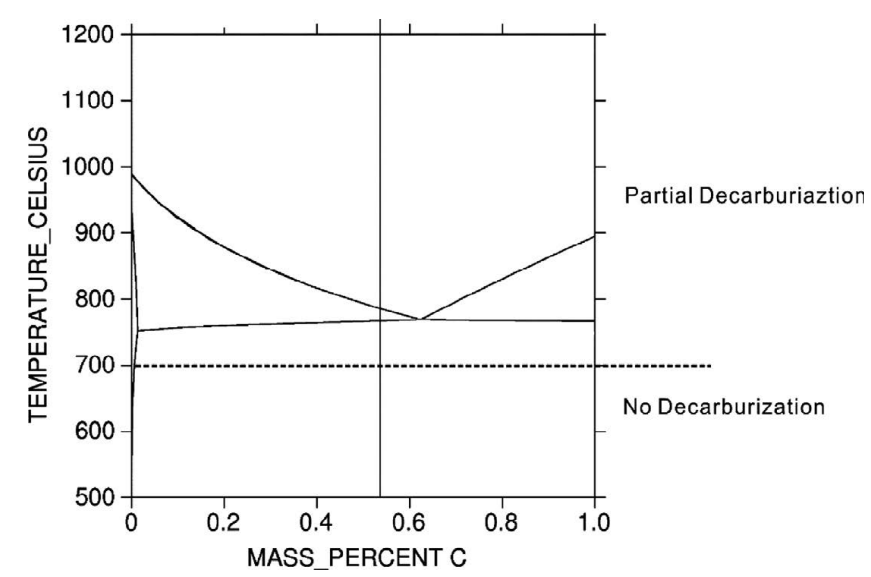

Fig. 9. Classification of decarburization types according to temperature in the phase diagram of $55 \mathrm{SiCr}$ when heated in the atmosphere of $2 \% \mathrm{O}_{2}$ and $98 \% \mathrm{~N}_{2}$. 
partial decarburization is found, and no abrupt drop of the thickness of decarburization will be detected.

\section{Conclusions}

By using a Muffle furnace (in ambient air) and a Simultaneous Thermal Analyzer (in the atmosphere of $2 \% \mathrm{O}_{2}$ and $98 \% \mathrm{~N}_{2}$ ), effects of temperature and oxygen concentration on the decarburization of $55 \mathrm{SiCr}$ spring steel were investigated at the temperature range of $500^{\circ} \mathrm{C}-1200^{\circ} \mathrm{C}$. The following conclusions were obtained.

(1) For $55 \mathrm{SiCr}$ spring steels heated in ambient air, the decarburization behavior can be divided roughly into five regions. In the region (a) $\mathrm{T} \geq 1200^{\circ} \mathrm{C}$ approximately, no decarburization occurs. In the region (b) $\mathrm{TG}<\mathrm{T}<1200^{\circ} \mathrm{C}$, only partial decarburization is found. In the region (c) $\mathrm{A}_{3}<\mathrm{T}<\mathrm{TG}$, both complete and partial decarburization are observed. In the region (d) $\mathrm{T}<\mathrm{A}_{3}$, only complete decarburization is found. In the region (e) $\mathrm{T}<\mathrm{A}_{1}$, no decarburization occurs.

(2) For $55 \mathrm{SiCr}$ spring steels heated in the atmosphere of $2 \% \mathrm{O}_{2}$ and $98 \% \mathrm{~N}_{2}$, the decarburization behavior can be divided into two regions. In the temperature lower than $700^{\circ} \mathrm{C}$, no decarburization occurs. In the temperature higher than $700^{\circ} \mathrm{C}$, only partial decarburization is found, and no abrupt drop of the thickness of decarburization will be detected.

(3) Complete decarburization is eliminated by decreas- ing the oxygen concentration to $2 \%$.

(4) It is infeasible to reduce the thickness of decarburization by decreasing oxygen concentration. Meanwhile, it is not possible to reduce the thickness of decarburization by increasing temperature when $55 \mathrm{SiCr}$ steel is heated in low oxygen concentration atmosphere.

\section{REFERENCES}

1) Y. Prawoto, M. Ikeda, S. K. Manville and A. Nishikawa: Eng. Fail. Anal., 15 (2008), 1155.

2) M. J. Gildersleeve: Mater. Sci. Technol., 7 (1991), 307.

3) A. K. Sinha: Physical Metallurgy Handbook, McGraw-Hill, New York, (2002), 933.

4) Y. Yamada: Materials for Springs, Springer, Berlin, (2007), 77.

5) J. F. Xiao, Y. Z. Liu, C. L. Zhang and C. Jiang: Heat Treat. Met., 35 (2010), 94 (in Chinese).

6) C. L. Zhang, L. Y. Zheng, Z. L. Yu, J. Chao and F. X. Jin: Int. J. Miner. Metall. Mater. 19 (2012), 116.

7) Y. Prawoto, M. A. Mat Yajid and K. J. Lee: J. King Saud Uni. Eng. Sci., 25 (2013), 141.

8) M. Nomura, H. Morimoto and M. Toyama: ISIJ Int., 40 (2000), 619.

9) S. Choi and S. V. D. Zwaag: ISIJ Int., 52 (2012), 549.

10) J. Baud, A. Ferrier, J. Manenc and J. Benard: Oxid. Met., 9 (1975), 69.

11) R. Y. Chen and W. Y. D. Yuen: Oxid. Met., 59 (2003), 433.

12) G. Parrish: Carburizing: Microstructures and Properties, ASM International, Materials Park, OH, (1999), 37.

13) N. Birks, G. H. Meier and F. S. Pettit: Introduction to the HighTemperature Oxidation of Metals, Cambridge University Press, Cambridge, (2006), 156.

14) H. Q. Wen, S. H. Xiang, Y. J. Zhang, M. D. Han and S. M. Tao: Baosteel Technol., 3 (2008), 44 (in Chinese).

15) J. Burke, J. Bell and D. R. Bourne: Acta Metall., 8 (1960), 864.

16) H. Abuluwefa, R. I. L. Guthrie and F. Ajerscht: Oxid. Met., 46 (1996), 423. 